\title{
Weight Advice Associated With Male Firefighter Weight Perception and Behavior
}

\author{
Austin L. Brown, PhD, ${ }^{1}$ Walker S.C. Poston, PhD, ${ }^{2}$ Sara A. Jahnke, PhD, ${ }^{2}$ C. Keith Haddock, PhD, ${ }^{2}$ \\ Sheng Luo, PhD, ${ }^{3}$ George L. Delclos, MD, ${ }^{1}$ R. Sue Day, $\mathrm{PhD}^{1}$
}

Introduction: The high prevalence of overweight and obesity threatens the health and safety of the fire service. Healthcare professionals may play an important role in helping firefighters achieve a healthy weight by providing weight loss counseling to at-risk firefighters. This study characterizes the impact of healthcare professional weight loss advice on firefighter weight perceptions and weight loss behaviors among overweight and obese male firefighters.

Methods: A national sample of 763 overweight and obese male firefighters who recalled visiting a healthcare provider in the past 12 months reported information regarding healthcare visits, weight perceptions, current weight loss behaviors, and other covariates in 2011-2012. Analyzed in 2013, four unique multilevel logistic regression models estimated the association between healthcare professional weight loss advice and the outcomes of firefighter-reported weight perceptions, intentions to lose weight, reduced caloric intake, and increased physical activity.

Results: Healthcare professional weight loss advice was significantly associated with self-perception as overweight $(\mathrm{OR}=4.78,95 \% \mathrm{CI}=2.16,10.57)$ and attempted weight loss $(\mathrm{OR}=2.06,95 \% \mathrm{CI}=1.25$, 3.38), but not significantly associated with reduced caloric intake $(\mathrm{OR}=1.26,95 \% \mathrm{CI}=0.82,1.95)$ and increased physical activity $(\mathrm{OR}=1.51,95 \% \mathrm{CI}=0.89,2.61)$, after adjusting for confounders.

Conclusions: Healthcare professional weight loss advice appears to increase the accuracy of firefighter weight perceptions, promote weight loss attempts, and may encourage dieting and physical activity behaviors among overweight firefighters. Healthcare providers should acknowledge their ability to influence the health behaviors of overweight and obese patients and make efforts to increase the quality and frequency of weight loss recommendations for all firefighters.

(Am J Prev Med 2015;49(4):589-593) @ 2015 American Journal of Preventive Medicine

\section{Introduction}

$\mathrm{M}$

ore than $75 \%$ of firefighters are overweight or obese. ${ }^{1}$ The high prevalence of overweight and obesity contributes to approximately 70,000

From the ${ }^{1}$ Division of Epidemiology, Human Genetics, and Environmental Sciences, School of Public Health, University of Texas Health Sciences Center at Houston, Houston, Texas; ${ }^{2}$ Center for Fire, Rescue, and EMS Health Research, Institute for Biobehavioral Health Research, National Development and Research Institutes, Leawood, Kansas; and ${ }^{3}$ Division of Biostatistics, School of Public Health, University of Texas Health Sciences Center at Houston, Houston, Texas

Address correspondence to: R. Sue Day, PhD, The University of Texas Health Sciences Center at Houston, School of Public Health, Division of Epidemiology, Human Genetics, and Environmental Sciences, Michael and Susan Dell Center for Healthy Living, 1200 Pressler, RAS E1027, Houston TX 77030. E-mail: rena.s.day@uth.tmc.edu.

$0749-3797 / \$ 36.00$

http://dx.doi.org/10.1016/j.amepre.2015.04.002 line-of-duty injuries and 100 fatalities annually in the U.S. ${ }^{2,3}$ Nearly $70 \%$ of overweight firefighters underestimate their current weight status, ${ }^{4}$ and more than half do not view themselves as overweight. ${ }^{5}$ Consequently, many overweight firefighters may not recognize the need to lose weight. Overweight individuals with accurate weight perceptions are more likely to initiate weight loss behaviors. ${ }^{6}$ In the general population, physician weight counseling increases the accuracy of patient weight perceptions, ${ }^{7,8}$ understanding of obesity risk, ${ }^{9}$ and appreciation for the benefits of weight loss. ${ }^{9}$ Healthcare professionals, therefore, have a responsibility to inform overweight firefighters about their weight and provide resources to assist firefighters achieve a healthy weight.

Our previous research found healthcare professionals provide weight advice to only $48 \%$ of obese and $12 \%$ of overweight firefighters. ${ }^{10}$ Healthcare professional weight 
advice is associated with increased readiness to lose weight, intentions to improve diet and physical activity, ${ }^{7,9}$ and weight loss attempts. ${ }^{6,8,11}$ However, results from the general population may not be generalizable to firefighters. This study characterizes the impact of healthcare professional weight loss advice on weight perceptions and weight loss behaviors of overweight and obese male firefighters.

\section{Methods}

\section{Study Sample}

This study used data from the Fuel 2 Fight (F2F) study (20112012). A description of the F2F design and methods has been published. ${ }^{12}$ Briefly, firefighters were recruited from 20 departments representing urban and rural communities across 14 U.S. states or territories. Trained data collectors traveled to fire departments to conduct assessments. All firefighters present at the time of assessments were invited to participate, with $>94 \%$ of the firefighters agreeing to participate. F2F was approved by ethics committees at the University of Texas School of Public Health and the National Development and Research Institutes.

\section{Measures}

BMI was calculated by dividing data collector-measured weight (in kilograms) by squared height (in meters). ${ }^{12}$ Body fat percentage, from bioelectrical impedance, ${ }^{13}$ and waist circumference were measured following standard procedures. ${ }^{14}$ Overweight and obesity categories were generated for BMI, waist circumference, and body fat percentage. ${ }^{14,15}$ Firefighters completed self-administered questionnaires assessing demographic, occupational, and medical histories. Questions regarding healthcare visits and weight loss behaviors were adapted from questions used in the general population. ${ }^{16}$ Participants reported any weight-related advice received from a healthcare professional during the past year, their current weight status, current weight loss attempts, and recent diet or exercise changes.

\section{Statistical Analysis}

In 2013, statistical analyses were performed using Stata, version 13 at a 5\% significance level. Analyses were restricted to male overweight and obese firefighters $(\mathrm{N}=795)$ who visited a healthcare professional in the past year (763 of 795). Self-reported healthcare professional weight advice represented the primary exposure. Self-reported weight perceptions, intentions to lose weight, reduce caloric intake, and increase physical activity served as four unique outcomes in multilevel logistic regression models, which accounted for correlation among individuals within the same department and adjusted for confounders. To avoid incorrectly classifying lean firefighters as overweight, a secondary analysis excluded firefighters in the healthy range for both body fat percentage $(<18 \%)$ and waist circumference $(<94 \mathrm{~cm}) .{ }^{14,15}$ ORs and associated 95\% CIs are reported for the relationship between healthcare professional weight loss advice and each outcome.

\section{Results}

Approximately 25\% of firefighters reported receiving healthcare professional advice to lose weight in the past year (Table 1). Older age, higher adiposity, and the presence of comorbidities were associated with firefighters recalling healthcare professional weight loss advice.

Approximately $40 \%$ of overweight and $8 \%$ of obese firefighters did not perceive themselves as overweight (data not shown). Firefighters who reported receiving healthcare professional advice to lose weight were more likely $(\mathrm{OR}=4.78,95 \% \mathrm{CI}=2.16,10.57)$ to perceive themselves as overweight after adjusting for covariates (Table 2). The association persisted after excluding 60 (8\%) BMI-defined overweight firefighters with both body fat percentage and waist circumference measurements in the healthy range $(\mathrm{OR}=4.01,95 \% \mathrm{CI}=1.81$, 8.92).

The prevalence of self-reported weight loss behaviors was high among overweight firefighters, as 65\% were currently attempting to lose weight, $63 \%$ had changed their diet, and $82 \%$ were exercising to lose or maintain weight (Table 2). In unadjusted models, healthcare professional weight advice was positively associated with firefighter attempts to lose weight $(\mathrm{OR}=4.14,95 \%$ $\mathrm{CI}=2.65,6.47)$, changes in diet to lose or maintain weight $(\mathrm{OR}=2.04,95 \% \mathrm{CI}=1.40,2.97)$, and increases in physical activity to lose or maintain weight $(\mathrm{OR}=1.77$, $95 \% \mathrm{CI}=1.09,2.89$ ). The positive relationship observed between healthcare professional weight loss advice and each behavior persisted after adjustment for covariates; however, only the association between weight advice and weight loss attempts remained statistically significant $(\mathrm{OR}=2.06,95 \% \mathrm{CI}=1.25,3.38)$. Exclusion of individuals with body fat percentage and waist circumference measurements in the healthy range negligibly impacted the results.

\section{Discussion}

The dangers of firefighting are compounded among overweight firefighters. In this national sample, most overweight firefighters (66\%) were currently trying to lose weight through diet (63\%) or exercise (82\%), suggesting many are aware of the need to lose weight. Similar to general population studies, ${ }^{6,8,11}$ healthcare professional weight advice was associated with moreaccurate weight perceptions and healthy weight loss behaviors in overweight and obese firefighters. Firefighters reporting advice to lose weight were four times more likely to consider themselves overweight and twice as likely to engage in weight loss attempts. Weight loss 
Table 1. Characteristics of Male Overweight and Obese Firefighters Stratified by Weight Advice, Fuel2Fight 2011-2012 ( $n=763)$

\begin{tabular}{|c|c|c|}
\hline & \multicolumn{2}{|c|}{$\begin{array}{l}\text { Healthcare professional weight advice } \\
\text { (past } 12 \text { months) }\end{array}$} \\
\hline & $\begin{array}{l}\text { Lose weight }(n=189) \\
\text { M (SD) }\end{array}$ & $\begin{array}{l}\text { Other }(n=574) \\
\text { M (SD) }\end{array}$ \\
\hline Age, years & $42.5(8.0)$ & $39.3(8.7)$ \\
\hline BMI, kg/m² & $32.3(4.2)$ & $28.8(3.2)$ \\
\hline Waist circumference, cm & $107.4(11.2)$ & $97.1(8.9)$ \\
\hline \multirow[t]{2}{*}{ Body fat, $\%$} & $29.0(6.8)$ & $23.4(5.8)$ \\
\hline & $n(\%)$ & $n(\%)$ \\
\hline Any comorbidities & $125(66)$ & $243(43)$ \\
\hline Depression (CESD-10 $\geq 4$ ) & 34 (19) & $87(16)$ \\
\hline Anxiety (self-reported) & $18(10)$ & $40(7)$ \\
\hline Smoking (past 30 days) & $28(15)$ & $113(20)$ \\
\hline \multicolumn{3}{|l|}{ Alcoholic intake (past 30 days) } \\
\hline Abstinent & 35 (19) & $80(14)$ \\
\hline 1-2 drinks/day & $78(42)$ & $214(38)$ \\
\hline 3-4 drinks/day & $43(23)$ & $160(28)$ \\
\hline$\geq 5$ drinks/day & $30(16)$ & $111(20)$ \\
\hline \multicolumn{3}{|l|}{ Rank in department } \\
\hline Firefighter & $120(64)$ & $394(70)$ \\
\hline Officer & $45(24)$ & $122(22)$ \\
\hline Chief & $10(5)$ & $19(3)$ \\
\hline Other & $12(6)$ & $28(5)$ \\
\hline Ethnic minority & $75(41)$ & $204(36)$ \\
\hline \multicolumn{3}{|l|}{ Relationship status } \\
\hline Long-term/married & $160(86)$ & $426(75)$ \\
\hline Single/divorced/separated & $27(14)$ & $138(25)$ \\
\hline \multicolumn{3}{|l|}{ Department type } \\
\hline Standard & $87(46)$ & $271(47)$ \\
\hline Wellness approach & $102(54)$ & $303(53)$ \\
\hline
\end{tabular}

Missing: Age ( $n=2)$; BMI ( $n=6)$; Waist circumference $(n=2)$; Body fat $(n=19)$; Comorbidities $(n=9)$; Depression ( $n=24)$; Anxiety $(n=8)$; Smoking ( $n=19)$; Alcohol $(n=12)$; Rank $(n=13)$; Ethnicity $(n=14)$; Relationship $(n=12)$.

CESD-10, Center for Epidemiologic Studies Depression Scale.

and exercise recommendations. ${ }^{9}$ Although research suggests BMI is an accurate measure in firefighters, ${ }^{1,17}$ concerns regarding BMI as a measure of adiposity exist because it does not discriminate between fat and lean mass. A sensitivity analysis, excluding BMI-defined overweight firefighters with low body fat percentage and waist circumference, did not meaningfully impact the results of this study.

\section{Limitations}

Limitations include a reliance on participant-reported data, which may be subject to bias. Further, weight counseling varies greatly with respect to patient and provider characteristics, ${ }^{18,19}$ but information related to weight advice frequency and quality was unavailable. Finally, the cross-sectional study design limits the ability to determine the direction of the relationship between weight advice and weight loss behavior, because firefighters engaged in weight loss activities may be more likely to recall weight loss conversations with a healthcare provider.

\section{Conclusions}

National firefighter standards recommend annual medical evaluations for career firefighters, providing healthcare professionals with an opportunity to deliver weight counseling. ${ }^{20}$ Although healthcare professional weight advice was positively associated with firefighter weight loss behavior in this study, the role of healthcare professionals in weight loss remains controversial and the effects of weight counseling are not consistent across studies. ${ }^{21,22}$ Healthcare provider pessimism about the benefits of weight loss counseling

advice was not significantly associated with firefighter use of physical activity and diet to lose weight. The weak association observed between weight advice and firefighter diet and exercise behavior may be attributable to poor-quality weight advice lacking explicit diet likely contributes to the low prevalence of firefighters receiving weight advice., ${ }^{9,10}$ This study may help providers overcome these barriers and increase the consistency of weight recommendations. Frequent, higherquality weight counseling has been associated with 
Table 2. Association Between Weight Loss Advice, Weight Perceptions, and Weight Loss Behavior Among Overweight/Obese Firefighters, Fuel2Fight 2011-2012

\begin{tabular}{|c|c|c|c|c|}
\hline & \multirow{2}{*}{$\begin{array}{c}\text { Weight perception } \\
\text { Overweight } \\
(n=532) \\
\text { OR }(95 \% \mathrm{Cl})\end{array}$} & \multicolumn{3}{|c|}{ Weight loss behavior } \\
\hline & & $\begin{array}{l}\text { Attempting to lose } \\
\text { weight }(n=497) \\
\text { OR }(95 \% \mathrm{Cl})\end{array}$ & $\begin{array}{c}\text { Change diet } \\
(n=477) \\
\text { OR }(95 \% \mathrm{CI})\end{array}$ & $\begin{array}{l}\text { Increase physical } \\
\text { activity }(n=622) \\
\text { OR }(95 \% \mathrm{Cl})\end{array}$ \\
\hline Model $1^{a}$ & $13.77(6.54,28.99)$ & $4.14(2.65,6.47)$ & $2.04(1.40,2.97)$ & $1.77(1.09,2.89)$ \\
\hline Model $2^{\mathrm{b}}$ & $4.78(2.16,10.57)$ & $2.06(1.25,3.38)$ & $1.26(0.82,1.95)$ & $1.51(0.89,2.61)$ \\
\hline Model $3^{c}$ & $4.01(1.81,8.92)$ & $2.20(1.31,3.70)$ & $1.30(0.82,2.06)$ & $1.60(0.91,2.83)$ \\
\hline
\end{tabular}

${ }^{a}$ Model 1 crude estimate.

${ }^{\mathrm{b}}$ Model 2 adjusted for age, BMI, prevalent comorbidities, minority status, and department wellness program.

${ }^{c}$ Model 3 adjusted for variables in Model 2, excludes firefighters with body fat $<18 \%$ and waist circumference $<94 \mathrm{~cm}(n=60)$.

weight loss intentions and behaviors. ${ }^{23}$ Limited research among firefighters further suggests health promotion programs should include efforts toward increasing compliance to physician-prescribed exercise plans and conducting regular health surveillance to help promote weight loss. ${ }^{24,25}$ Therefore, healthcare professionals should consider incorporating additional resources and follow-up appointments into their standard weight counseling practice.

This work was supported by the Assistance to Firefighters Grants program managed by the Federal Emergency Management Agency in the Department of Homeland Security (EMW2009-FP-01971, EMW-2010-FP-01812).

\section{References}

1. Poston WS, Haddock CK, Jahnke SA, Jitnarin N, Tuley BC, Kales SN. The prevalence of overweight, obesity, and substandard fitness in a population-based firefighter cohort. J Occup Environ Med. 2011;53 (3):266-273. http://dx.doi.org/10.1097/JOM.0b013e31820af362.

2. Fahy RF, LeBlanc PR, Molis JL. Firefighter Fatalities in the United States-2012. Quincy, MA: National Fire Protection Association, 2013.

3. Karter MJ, Molis JL. U.S. Firefighter Injuries-2012. Quincy, MA: National Fire Protection Association; 2013.

4. Baur DM, Christophi CA, Kales SN. Metabolic syndrome is inversely related to cardiorespiratory fitness in male career firefighters. J Strength Cond Res. 2012;26(9):2331-2337. http://dx.doi.org/10.1519/JSC. 0b013e31823e9b19.

5. Kay BF, Lund MM, Taylor PN, Herbold NH. Assessment of firefighters' cardiovascular disease-related knowledge and behaviors. J Am Diet Assoc. 2001;101(7):807-809. http://dx.doi.org/10.1016/S00028223(01)00200-0.

6. Zapka J, Lemon SC, Estabrook B, Rosal MC. Factors related to weight loss behavior in a multiracial/ethnic workforce. Ethn Dis. 2009;19 (2):154-160.

7. Post RE, Mainous AG, Gregorie SH, Knoll ME, Diaz VA, Saxena SK. The influence of physician acknowledgment of patients' weight status on patient perceptions of overweight and obesity in the United States. Arch Intern Med. 2011;171(4):316-321. http://dx.doi.org/10.1001/ archinternmed.2010.549.
8. Singh S, Lopez-Jimenez F. Medically diagnosed overweight and weight loss in a U.S. national survey. Prev Med. 2010;51(1):24-26 http://dx.doi.org/10.1016/j.ypmed.2010.04.013.

9. Huang J, Yu H, Marin E, Brock S, Carden D, Davis T. Physicians' weight loss counseling in two public hospital primary care clinics. Acad Med. 2004;79(2):156-161. http://dx.doi.org/10.1097/00001888200402000-00012.

10. Wilkinson ML, Brown AL, Poston WS. Haddock CK, Jahnke SA, Day RS. Physician weight recommendations for overweight and obese firefighters, United States, 2011-2012. Prev Chronic Dis. 2014;11: E116.

11. Rose SA, Poynter PS, Anderson JW, Noar SM, Conigliaro J. Physician weight loss advice and patient weight loss behavior change: a literature review and meta-analysis of survey data. Int J Obes (Lond). 2013;37 (1):118-128. http://dx.doi.org/10.1038/ijo.2012.24.

12. Poston WS, Haddock CK, Jahnke SA, Jitnarin N, Day RS. An examination of the benefits of health promotion programs for the national fire service. BMC Public Health. 2013;13:805. http://dx.doi.org/ 10.1186/1471-2458-13-805.

13. Rubiano F, Nunez C, Heymsfield SB. A comparison of body composition techniques. Ann N Y Acad Sci. 2000;904:335-338. http://dx. doi.org/10.1111/j.1749-6632.2000.tb06477.x.

14. National Heart, Lung, and Blood Institute. Clinical Guidelines on the Identification, Evaluation, and Treatment of Overweight and Obesity in Adults. Bethesda, MD: NIH, 1998: 98-4083.

15. American Council on Exercise. What Are the Guidelines for Percentage of Body Fat Loss? San Diego, CA: American Council on Exercise, 2009.

16. CDC. Behavioral Risk Factor Surveillance System Questionnaire (2010). Atlanta, GA: CDC, 2010.

17. Jitnarin N, Poston WS, Haddock CK, Jahnke S, Tuley BC. Accuracy of body mass index-defined overweight in fire fighters. Occup Med (Lond). 2013;63(3):227-230. http://dx.doi.org/10.1093/occmed/ kqs213.

18. Bleich SN, Bennett WL, Gudzune KA, Cooper LA. Impact of physician BMI on obesity care and beliefs. Obesity (Silver Spring). 2012;20 (5):999-1005. http://dx.doi.org/10.1038/oby.2011.402.

19. Cox ME, Yancy WS Jr, Coffman CJ, et al. Effects of counseling techniques on patients' weight-related attitudes and behaviors in a primary care clinic. Patient Educ Couns. 2011;85(3):363-368. http://dx.doi.org/ 10.1016/j.pec.2011.01.024

20. NFPA 1582, Standards on Comprehensive Occupational Medicine Programs for Fire Departments. Quincy, MA: National Fire Protection Association; 2006.

21. Singh S, Lopez-Jimenez F. Medically diagnosed overweight and weight loss in a U.S. national survey. Prev Med. 2010;51(1):24-26. http://dx.doi.org/10.1016/j.ypmed.2010.04.013. 
22. Noel PH, Wang CP, Bollinger MJ, et al. Intensity and duration of obesity-related counseling: association with 5-Year BMI trends among obese primary care patients. Obesity (Silver Spring). 2012;20(4):773-782. http://dx.doi.org/10.1038/oby.2011. 335.

23. Jay M, Gillespie C, Schlair S, Sherman S, Kalet A. Physicians' use of the 5 As in counseling obese patients: is the quality of counseling associated with patients' motivation and intention to lose weight? $B M C$
Health Serv Res. 2010;10:159. http://dx.doi.org/10.1186/1472-696310-159.

24. Reid EL, Morgan RW. Exercise prescription: a clinical trial. Am J Public Health. 1979;69(6):591-595. http://dx.doi.org/10.2105/AJPH.69.6.591.

25. Poston WS, Jitnarin N, Haddock CK, et al. The impact of surveillance on weight change and predictors of change in a population-based firefighter cohort. J Occup Environ Med. 2012;54(8):961-968. http://dx.doi.org/10.1097/JOM.0b013e31825296e0. 